\title{
Laparoscopic Sleeve Gastrectomy Achieves Normalization of C-reactive Protein at 18 months after Surgery
}

V Falk, D Pace, C Smith, D Boone, L Twells Memorial University of Newfoundland

\section{Introduction}

Obesity leads to a chronic state of inflammation and elevated C-reactive protein (CRP). Bariatric surgery achieves both long-term weight loss and reduction in inflammatory markers. We aim to examine the effect of laparoscopic sleeve gastrectomy (LSG) on CRP levels.

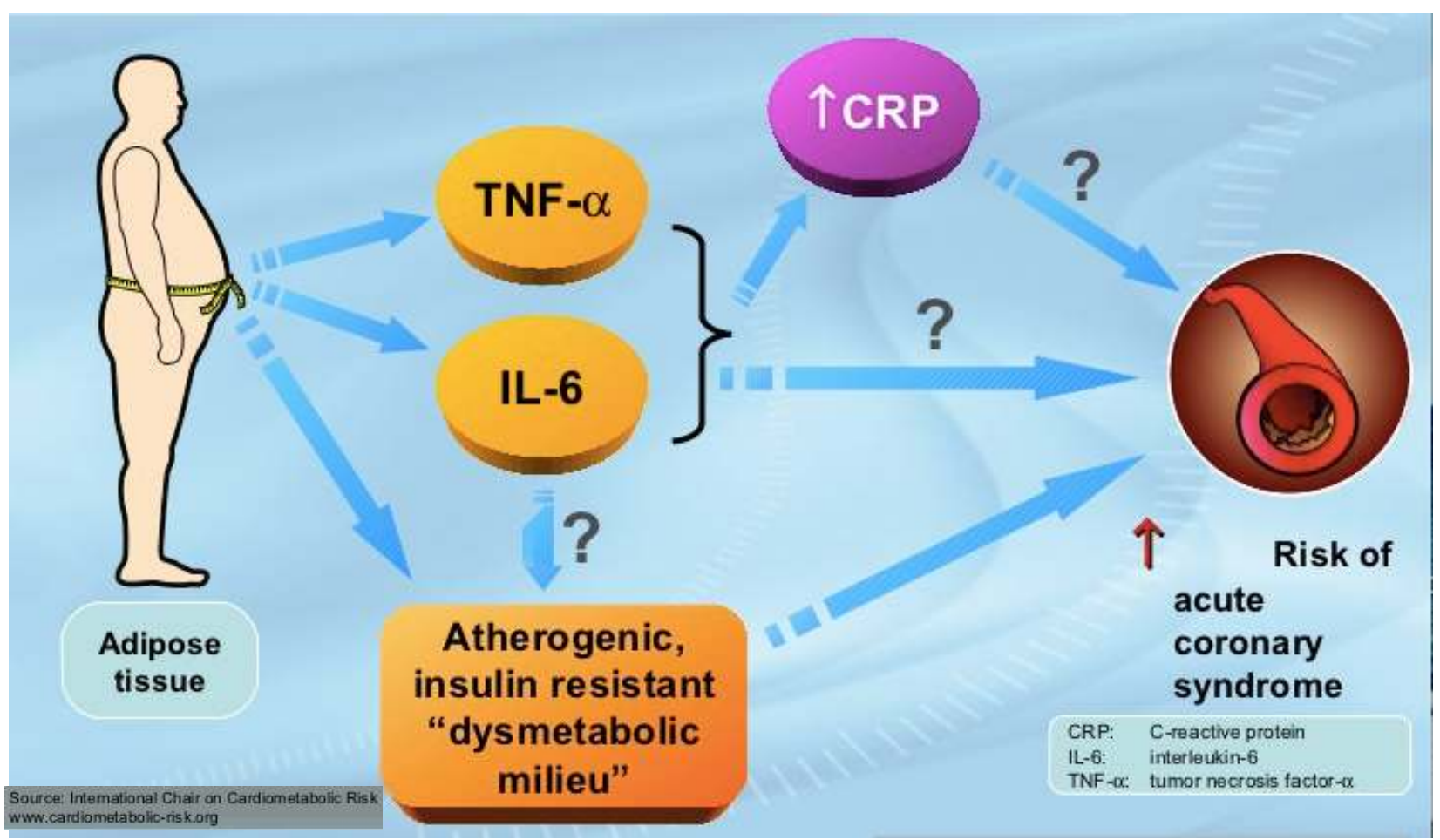

\section{Methods}

This is a retrospective review of LSG patients operated from May 2011 and February 2014.

- Primary outcome: CRP level at 6, 12, and 18 months post-op

- Secondary outcomes: weight loss, 30-day complications, and mortality

\section{Results}

209 patients underwent LSG with average preoperative BMI $49.2 \mathrm{~kg} / \mathrm{m}^{2}$ (min $35.0 \mathrm{~kg} / \mathrm{m}^{2}$, max 67.4 $\mathrm{kg} / \mathrm{m}^{2}$ ) and , average age 43.4 years ( $\min 22$ years, max 70 years). $82 \%$ were female. The most common comorbidities were hypertension $(55.0 \%)$, obstructive sleep apnea (46.4\%), dyslipidemia $(42.1 \%)$ and diabetes (37.8\%). The total average $\%$ BMIL was $59.8 \% \mathrm{~kg} / \mathrm{m}^{2}$ after 12 months and $58.5 \% \mathrm{~kg} / \mathrm{m}^{2}$ after 24 months.

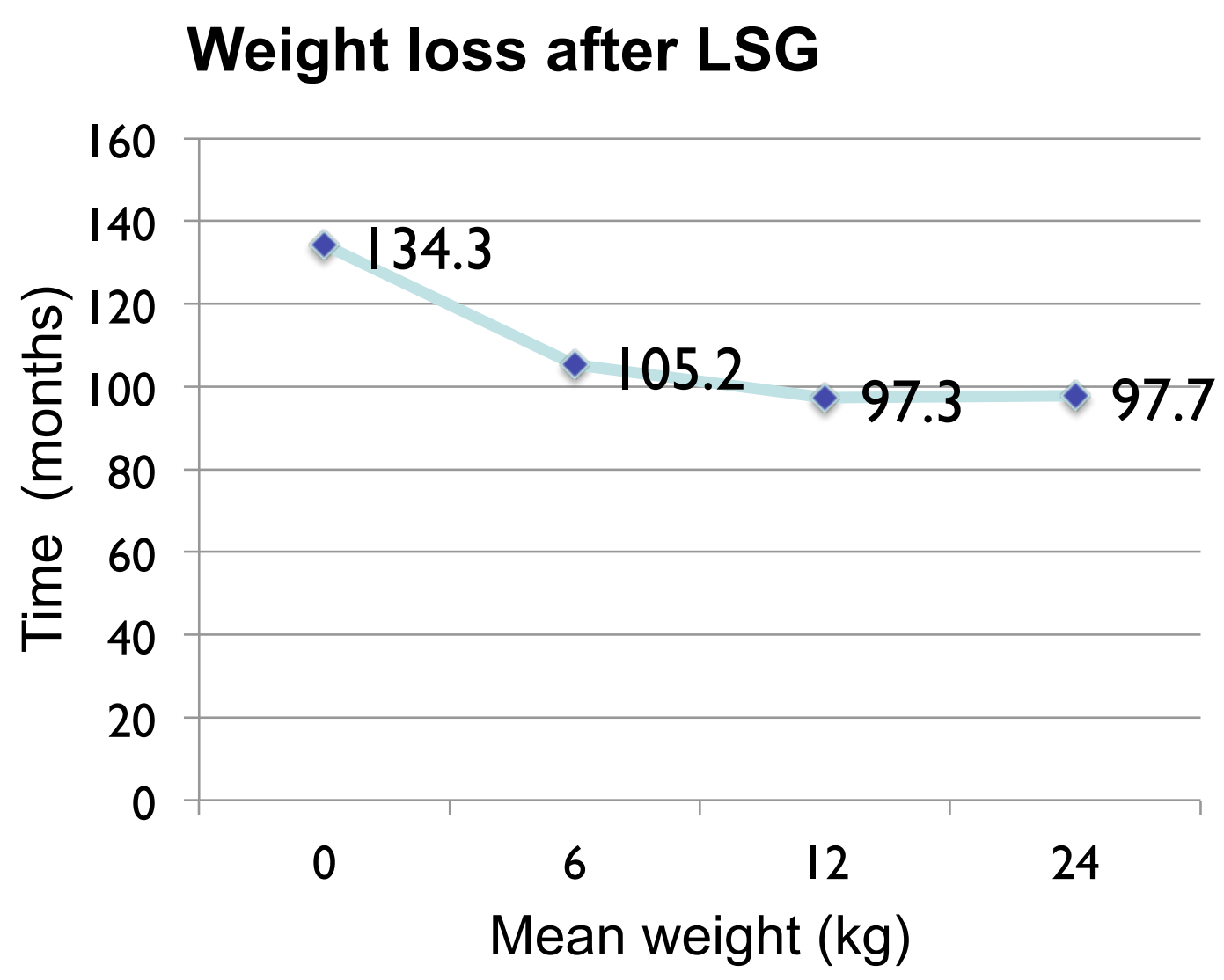

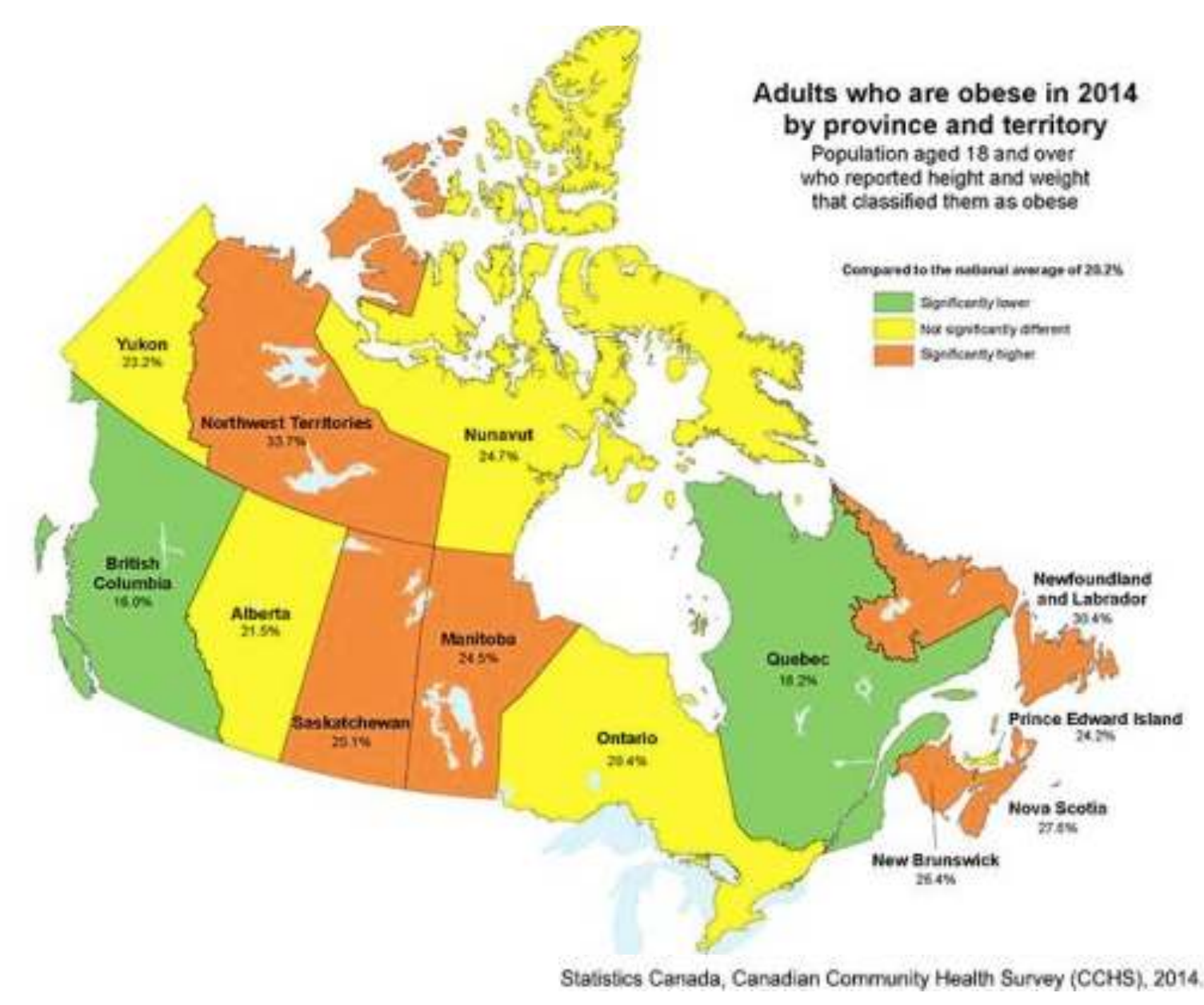

The mean pre-op CRP level was $11.53 \mathrm{mg} / \mathrm{L}$ (min 0.6 , max 49.3). BMI was significantly higher among patients with elevated CRP $\left(50.5 \mathrm{~kg} / \mathrm{m}^{2}\right.$ versus 47.6 $\left.\mathrm{kg} / \mathrm{m}^{2}, \mathrm{p}=0.019\right)$. Pre-operatively, 89 patients (Group N) had normal ( $\leq 8 \mathrm{mg} / \mathrm{L})$ and 114 patients (Group E) had elevated (>8mg/L) CRP levels.

\begin{tabular}{lccc}
\hline & $\begin{array}{c}\text { Normal } \\
\text { pre-op } \\
\text { CRP } \\
(\mathbf{n = 8 9})\end{array}$ & $\begin{array}{c}\text { Elevated } \\
\text { pre-op } \\
\text { CRP } \\
(\mathbf{n = 1 1 4})\end{array}$ & p-value \\
\hline $\begin{array}{l}\text { Mean pre-op } \\
\text { CRP (mg/L) }\end{array}$ & $4.66 \pm 1.99$ & $16.9 \pm 8.84$ & $<0.001$ \\
\hline $\begin{array}{l}\text { Mean CRP } \\
\text { I-year post- } \\
\text { op (mg/L) }\end{array}$ & $2.04 \pm 3.26$ & $8.43 \pm 20.44$ & 0.023 \\
$\begin{array}{l}\text { Mean CRP } \\
\text { I8-months } \\
\text { post-op } \\
\text { (mg/L) }\end{array}$ & $2.85 \pm 5.72$ & $5.33 \pm 6.79$ & 0.076 \\
\hline
\end{tabular}

Group E had significantly more females and higher mean BMI. Overall 30-day complication rate was $15.3 \%$ (13.4\% minor and $1.9 \%$ major). While overall complications were higher in Group N (19.1\%) compared to Group E (12.3\%), this was not statistically significant $(p=0.238)$. No mortality occurred.

\section{Conclusion}

LSG leads to significant decrease in mean CRP levels, which normalize at 18 months postoperative. Female gender and $\mathrm{BMI}>50 \mathrm{~kg} / \mathrm{m}^{2}$ were associated with elevated CRP levels. Elevated CRP levels did not correlate with post-operative complication rate. 